\title{
VIVEMOS NO PAÍS DAS FINANÇAS PÚBLICAS MAL-ASSOMBRADAS
}

Coluna publicada em 22.8.2017: <https://www.conjur.com.br/2017-ago-22/ contas-vista-vivemos-pais-financas-publicas-mal-assombradas $>$

Nos últimos dias a crise econômica que parece não cessar trouxe à tona um dos muitos problemas enfrentados pelo Direito Financeiro, mais especificamente pelos orçamentos públicos. O orçamento, lei já reconhecida como a mais importante logo após a Constituição, ${ }^{1}$ tem múltiplas funções atualmente, destacando-se o controle, a gestão e o planejamento, tendo a transparência assumido relevância fundamental para que essas funções sejam cumpridas.

$\mathrm{O}$ orçamento deve conter todas as receitas e despesas, expondo a atividade financeira do Estado, e deixar claro o que é feito com o dinheiro público. Um orçamento bem elaborado, com clareza, abrangência e transparência não só orienta toda a administração pública, como também permite à sociedade, com todos os agentes sociais e econômicos, ter maior segurança no planejamento de suas próprias atividades. Um instrumento que sempre foi e é cada vez mais indispensável para o desenvolvimento econômico estável e equilibrado.

Nosso orçamento experimentou um longo caminho para chegar onde está. E, como se verá, falta muito para atingir o ideal. Ainda precisamos avançar, e notícias recentes indicam retrocessos, mostrando que há ainda obstáculos a vencer, e não são poucos.

"Capitais criam 'orçamentos paralelos' para ocultar gastos e fechar as contas", noticiou a Folha de S.Paulo em 7 de agosto de 2017. ${ }^{2}$ Elenca a notícia as várias dis-

1 Min. Carlos Ayres Britto, ADI-MC 4.048-1/DF, j. 14.5.2008, p. 92 dos autos.

2 <http://wwwl.folha.uol.com.br/cotidiano/2017/08/1907747-capitais-criam-orcamentos-paralelos-para-ocultar-gastos-e-fechar-as-contas.shtml>. 
torções observadas na execução orçamentária de cidades brasileiras, onde se constataram operaçōes que "contornavam" a transparência das informações orçamentárias, como Porto Alegre, em que gastos ocorriam "na prateleira"; ou Curitiba, em que foi descoberta a existência de um sistema de execução orçamentária paralelo ao oficial. E no Rio de Janeiro, despesas executadas "desapareciam" do sistema por meio de um "servidor fictício". E, assim, com "receitas bilionárias, os três municípios descobriram 'orçamentos paralelos', descolados das contas oficiais e nos quais centenas de gastos eram feitos de maneira informal, sem nenhum tipo de registro no orçamento". ${ }^{3}$

A realização de despesa pública submete-se a um regime jurídico próprio e rigoroso, para garantir a legalidade e a correta aplicação dos recursos, e tem várias fases que precisam ser cumpridas. Inicia-se com o empenho da despesa, "ato emanado de autoridade competente que cria para o Estado obrigação de pagamento pendente ou não de implemento de condição", reservando-se o valor no orçamento para permitir o pagamento, sendo então o valor liquidado para só então proceder-se ao pagamento (Lei 4.320/1964, arts. 58 a 65). No entanto, constataram-se casos de determinação da execução das despesas sem prévio empenho, dando origem a um verdadeiro "caixa dois", ficando as obrigaçôes do Poder Público, como sugere a notícia, em uma verdadeira "nuvem orçamentária", sem registro no orçamento. Criavam-se assim "esqueletos", com obrigações de pagamentos "escondidas no armário", que poderiam aparecer a qualquer momento e sem aviso, onerando os próximos gestores, surpreendidos com gastos sem qualquer previsão ou registro.

Em um dos exemplos citados na notícia, o prefeito Marchezan Júnior, de Porto Alegre, informou ter encontrado R \$ 20 milhões em despesas "na prateleira", sem empenho, o equivalente a 1,7\% do orçamento; em outro exemplo, Rafael Greca, prefeito de Curitiba, diz ter encontrado ainda mais, $\mathrm{R}$ \$ 614 milhões, em despesas sem empenho, o equivalente a $7 \%$ do orçamento.

São operações que violam os preceitos da legislação financeira, e já foram apuradas pelo sistema de fiscalização, como se pode constatar de decisões do Tribunal de Contas da União: "A assunção de dívida com fornecedores originária de despesas não registradas na contabilidade indica que essas foram realizadas sem prévio empenho e não observaram o princípio contábil da competência, o que viola o art. $42 \mathrm{da}$ Lei Complementar 101/2000 (LRF) e os artigos 35, 60, 88 e 90 da Lei 4320/1964"; ${ }^{4}$

Notícia citada.

4 Acórdão 11461/2011, enunciado. 
"É ilegal a autorização para realizar despesa sem prévio empenho, pois contraria o art. 60 da Lei 4.320/1964".

Essa realização de despesas sem respaldo nas dotações orçamentárias e sem prévio empenho atenta contra diversos dispositivos legais, como mencionado, demonstrando o pouco caso e a falta de seriedade dispensados às normas de Direito Financeiro. Disso resulta total insegurança aos contratantes, falta de transparência e ausência de planejamento, dificultando sobremaneira a fiscalização, dando margem a toda sorte de irregularidades, mau uso e desvio de recursos públicos.

Mas não é só a realização de despesas sem o necessário empenho prévio que provoca essas distorções; no Rio de Janeiro, como consta da notícia, empenhos eram cancelados, e despesas que deveriam ser pagas "desapareciam" temporariamente, para evitar que contabilmente constassem como valores a pagar deixados para os exercícios financeiros subsequentes.

Já chamamos a atenção em colunas anteriores para várias questôes que colaboram para esse déficit de transparência orçamentária. É o caso das despesas que ficam à margem do orçamento por razões várias, conhecidas como off-budget expenditures (evidenciando que o problema não é uma exclusividade nacional...), o que se pode verificar na ampla gama de "gastos tributários", como os benefícios creditícios que tratamos na coluna BNDES tem o dever de colaborar com a transparência dos gastos públicos. ${ }^{6}$

Irregularidades nas despesas de final de ano, com transferência abusiva de restos a pagar para o exercício seguinte, criam o que também tem sido denominado um "orçamento paralelo" que o gestor deve cumprir no exercício subsequente, tendo em vista as muitas despesas já empenhadas e não pagas no exercício anterior. Já se transformaram em prática corriqueira na administração pública, estando presentes nos vários entes federados. ${ }^{7}$

As famosas "pedaladas fiscais" também importaram em postergação de pagamentos de forma a que ficassem "escondidos" na contabilidade pública e obscurecessem despesas no orçamento. Foram severamente punidas com o afastamento da Presidente de seu cargo por impeachment. Mas parece que, apesar disso, não foi suficiente para fazer com que os governantes tenham respeito pelas normas de $\mathrm{Di}$ reito Financeiro.

É uma pena, pois o avanço do Direito Financeiro é um caminho sem volta.

Acórdão 423/2011, enunciado. No mesmo sentido: Acórdãos TCU 7.206/2012 e 1.335/2012.

6 Publicada nesta edição, p. 411-416.

7 O final de ano, as dividas e os "restos a pagar", nesta edição, p. 215-218. 
Retomando o que havia mencionado no início da coluna, a evolução dos orçamentos percorreu um longo caminho. Nesse percurso, cabe destaque aos princípios da unidade e da universalidade, bem como do orçamento bruto, que buscam a plenitude orçamental. São regras clássicas do orçamento - justamente aquelas que permitem sua adequada organização para atingir os fins nele designados. A Lei 4.320/1964, logo em seu artigo 2o, caput, estabelece que a "Lei de Orçamento conterá a discriminação da receita e despesas de forma a evidenciar a política econômico-financeira e o programa de trabalho do governo, obedecidos os princípios de unidade, universalidade e anualidade", especificando e detalhando seu conteúdo $\left(\$ \$ 1^{\circ}\right.$ e $\left.2^{\circ}\right)$; "compreenderá todas as receitas, inclusive as operaçôes de crédito autorizadas por lei" (art. 30), e "todas as receitas e despesas constarão da Lei de Orçamento pelos seus totais, vedadas quaisquer deduçōes" (art. $6^{\circ}$ ). O princípio da unidade, destaca Giuliani Fonrouge, permite apreciar se há equilíbrio orçamentário (pois todas as despesas e receitas estão contidas em um único documento), permite conhecer a magnitude do orçamento, dificulta manobras contábeis e permite o controle parlamentar. ${ }^{8}$ Referindo-se à universalidade, Heleno Torres destaca que "a dispersão de receitas ou despesas em distintos orçamentos não asseguraria transparência valorativa das finanças públicas, daí a necessidade de ter-se a acomodação de todos em um documento único, para o controle das finanças públicas", decorrendo da exigência do "holismo orçamentário, a partir da unidade que exige todas as receitas e despesas identificadas no orçamento". Esse conjunto de princípios mostra ser necessário que a autoridade orçamentária tenha conhecimento do conjunto das finanças para que tome sua decisão e, assim, exerça seu poder de autorização e controle, sem que seja induzida a erro. ${ }^{10} \mathrm{E}$ se a Constituição prevê, no artigo $165, \$ 5^{\circ}$, a separação da lei orçamentária em três partes (o orçamento fiscal, de investimentos das estatais e da seguridade social), isto não significa o afastamento do princípio da unidade. Ao contrário, todas as três peças compõem um mesmo documento, dividido de forma a conferir maior racionalidade a cada um de seus componentes, mas levados em conjunto ao Poder Legislativo. São princípios orçamentários que não admitem desvios, como está ocorrendo. Um retrocesso inaceitável.

8 GIUliAni FONROUGE, Carlos M. Derecho Financiero. 5. ed. Buenos Aires: Depalma, 1993. vol. 1. p. 184-185.

9 Direito Constitucional Financeiro. São Paulo: RT, 2014. p. 379.

10 Ver, a propósito, LOCHAGIN, Gabriel. A unificação dos orçamentos públicos pela Constituição de 1988. In: CONTI, José Mauricio; SCAFF, Fernando F. Orçamentos públicos e Direito Financeiro. São Paulo: RT, 2011, p. 198. 
Do jeito que as coisas caminham, persistindo a crise e a consequente falta de recursos, com a criatividade e o "jeitinho" brasileiro atuando "a todo vapor", a doutrina do Direito Financeiro terá daqui a pouco que incorporar ao seu vocabulário a expressão "orçamento-fantasma", em substituição à referência "peça de ficção"! Como se já não bastasse a "súmula-fantasma"... ${ }^{11}$ Receio que os Tribunais de Contas constatem que, quanto mais fiscalizam, mais assombração aparece!

Esse verdadeiro "mundo" de orçamentos paralelos, caixas-pretas, súmulas-fantasmas e esqueletos escondidos no armário nos coloca em um verdadeiro "museu de horrores" financeiro. E são tantos os envolvidos e tantas as irregularidades, que dessa vez não vai dar para dizer que o culpado é somente o mordomo...

11 Benefícios fiscais, partilha de receitas e a "súmula-fantasma" do STF, nesta edição, p. 35-40. 
